\title{
A multivariate analysis of socioeconomic and attitudinal factors predicting commuters' mode of travel
}

\author{
KEVIN J. FLANNELLY and MALCOLM S. MCLEOD, JR. \\ Center for Psychosocial Research, Honolulu, Hawaii
}

\begin{abstract}
A random sample of workers was surveyed to assess the influence of different variables thought to play a role in the decision to commute by a particular travel mode. Univariate analyses revealed significant differences between bus riders $(n=125)$ and car commuters $(n=547)$ on several independent socioeconomic and attitudinal factors, and discriminant analysis correctly classified three types of commuters with 58\% -71\% accuracy, using these measures. Solo drivers $(n=265)$ and carpoolers $(n=282)$ differed in their attitudes about carpooling and driving alone, although both groups, as well as bus riders, were favorably disposed to automobile travel. The generally positive attitude of all commuters toward the automobile is discussed in terms of the car's ability to reduce the information costs involved in traveling.
\end{abstract}

For over a decade, various governmental and nongovernmental agencies have promoted carpooling and other "ridesharing" measures (including mass transit) as means to reduce traffic congestion, pollution, and energy consumption. In general, advertising campaigns that appealed to people's sense of social responsibility proved ineffective in getting people to "share a ride" to work (Baerwald, 1985; Kostyniuk, 1982). Promotional strategies emphasizing the personal economic benefits of carpooling have not fared much better (Baerwald, 1985), and mass transit ridership has been in continuous decline for decades (Behnke \& McLeod, 1984).

A major problem with attempts to entice people out of their automobiles is that little is known about why people choose a given mode of travel (i.e., mode choice). Some studies indicate that psychological factors play a major role, whereas others suggest that mode choice is primarily an economic decision (Hartgen, 1974; Kostyniuk, 1982). Early multivariate studies undertaken to determine the relative contributions of socioeconomic and psychological variables showed promise (e.g., Johnson, 1978; Paine, Nash, Hille, \& Brunner, 1969; Tischer \& Dobson, 1979), but little research has been done along these lines in recent years. The present study extends these research efforts to examine the factors influencing commuters' choice of travel mode.

\section{METHOD}

\section{Survey Instrument}

The survey instrument collected information on the participants' travel behavior, their socioeconomic characteristics, their attitudes about the

Requests for reprints should be sent to Kevin J. Flannelly, Center for Psychosocial Research, 777 Kapiolani Boulevard, Room 1824, Honolulu, HI 96813. importance of the automobile in meeting their transportation needs, their evaluation of various characteristics of carpooling and driving alone, and their attitudes about the societal benefits of the two. Sections 3-5 of the questionnaire asked participants to rate their attitudes on a scale of 0-10. Some of the advantages of using this type of rating scale are discussed by McLeod, Flannelly, and Henderson (1988, in press) and Benjamin and Sen (1982).

Principal-component factor analysis suggested that the natural correlations among the items in the instrument could be accounted for by a minimum of six factors. Identical factor structures were produced by promax and varimax rotation methods.

The section dealing with socioeconomic variables was comprised of two factors: (1) household size and number of cars and drivers per household, and (2) marital status and household income. Factor loadings ranged from .67-.90.

Participants' attitudes about the importance of the automobile represented a common dimension, with all items loading on a single factor (loadings $=.46-.84$ ). Attitudes about the service characteristics of carpooling and driving alone formed two separate factors: the service characteristics of (1) carpooling and of (2) driving alone. The factor loadings for carpooling and driving alone were .74-.85 and .61-.81, respectively. The cost of each mode was not a component of either factor. Attitudes toward the societal benefits of the two modes formed a single dimension, with attitudes about driving alone weighted positively $(.80-.83)$ and carpooling weighted negatively $(-.69--.72)$ on this factor

\section{Participants}

The questionnaire was distributed to roughly 1,000 people working in downtown Honolulu (the return rate was $74 \%$ ). Participants were grouped into three categories: bus riders-commute regularly (3 or more days per week) by bus $(n=125)$, carpoolers-regularly commute by car with at least one other person $(n=282)$, and solo drivers-usually drive alone to work $(n=265)$. Data from participants who did not fall into any of these three categories were not analyzed.

The sex ratio of the sample was virtually 50:50: 340 males and 332 females. Almost $95 \%$ of the participants were licensed drivers.

\section{RESULTS}

Solo drivers and carpoolers said roughly two-thirds of their weekly driving mileage was devoted to the work commute. Less than $15 \%$ of the driving mileage of bus 
riders was used for commuting. Groups tended to distribute the remainder of their driving mileage about equally (24\%-33\% of the remainder) among shopping, family chores, and recreation.

Table 1 compares the socioeconomic characteristics of participants. Unweighted-means analyses of variance (ANOVAs) showed that the three types of commuters differed significantly on four of the six measures, with $F \mathrm{~s}(2,669)$ ranging from 4.70 to 14.64 (all $p s<.01$ ). Planned comparisons revealed that solo drivers and carpoolers differed reliably from bus riders, but not from each other, on these same measures. Although the proportions of married and unmarried people in the solo driver and bus rider categories were roughly comparable, married people were disproportionately represented in the carpooler category $\left[\chi^{2}(2)=73.1, p<.001\right]$.

Discriminant analysis, using the four measures that differed significantly among groups and marital status, correctly classified participants as bus riders and carpoolers with $55 \%$ and $64 \%$ accuracy, respectively. Solo drivers were accurately classified only $38 \%$ of the time.

Table 2 shows that significant differences exist among groups in their attitudes about the importance of the automobile for various kinds of travel, with $F \mathrm{~s}(2,669)$ ranging from 11.48 to 48.77 (all $p s<.01$ ). Subsequent tests showed that both solo drivers and carpoolers differed from bus riders, but not from each other, on all measures. Discriminant analysis based upon these ratings accurately classified $76 \%$ of bus riders, $61 \%$ of carpoolers, and $29 \%$ of solo drivers.

Table 3 presents the mean attitude ratings for various characteristics of driving alone and carpooling. The first six items describe transportation service characteristics,

Table 1

Description of Different Types of Commuters in Terms of Socioeconomic Characteristics

\begin{tabular}{|c|c|c|c|c|c|c|}
\hline \multirow[b]{3}{*}{ Measure } & \multicolumn{6}{|c|}{ Type of Commuter } \\
\hline & \multicolumn{2}{|c|}{ Solo Driver } & \multicolumn{2}{|c|}{ Carpooler } & \multicolumn{2}{|c|}{ Bus Rider } \\
\hline & $M$ & $S D$ & $M$ & $S D$ & $M$ & $S D$ \\
\hline Household income & 40.8 & 15.9 & 43.1 & 14.6 & 34.2 & $15.5 *$ \\
\hline Household size & 3.3 & 1.7 & 3.7 & 1.4 & 3.1 & $1.5^{*}$ \\
\hline Cars/household & 2.3 & 1.1 & 2.1 & 0.9 & 1.7 & $1.6^{*}$ \\
\hline Drivers/household & 2.3 & 1.1 & 2.5 & 1.0 & 2.2 & $1.1 *$ \\
\hline Years of age & 41.7 & 9.7 & 41.2 & 9.7 & 40.1 & 11.1 \\
\hline Years of school & 16.2 & 3.2 & 15.8 & 2.5 & 16.2 & 2.6 \\
\hline
\end{tabular}

Note-Household income given in thousands of dollars. ${ }^{*} p<.01$.

Table 2

Commuters' Ratings of the Importance of an Automobile for Various Trip Purposes

\begin{tabular}{|c|c|c|c|c|c|c|}
\hline \multirow[b]{3}{*}{ Trip Purpose } & \multicolumn{6}{|c|}{ Type of Commuter } \\
\hline & \multicolumn{2}{|c|}{ Solo Driver } & \multicolumn{2}{|c|}{ Carpooler } & \multicolumn{2}{|c|}{ Bus Rider } \\
\hline & $M$ & $S D$ & $M$ & $S D$ & $M$ & $S D$ \\
\hline Work & 9.1 & 2.1 & 8.9 & 2.2 & 3.3 & $3.7 *$ \\
\hline Shopping & 8.5 & 2.7 & 8.3 & 2.2 & 7.3 & $3.3 *$ \\
\hline Chores & 8.7 & 2.5 & 8.9 & 2.0 & 7.6 & $3.0^{*}$ \\
\hline Recreation & 8.3 & 3.0 & 8.5 & 2.5 & 7.6 & 2.9* \\
\hline
\end{tabular}

Table 3

Commuters' Mean Attitude Ratings of Various Characteristics of Carpooling and Driving Alone

Type of Commuter

\begin{tabular}{|c|c|c|c|c|c|c|}
\hline \multirow[b]{3}{*}{ Characteristic } & \multicolumn{6}{|c|}{ 1ype or Commuter } \\
\hline & \multicolumn{2}{|c|}{ Solo Driver } & \multicolumn{2}{|c|}{ Carpooler } & \multicolumn{2}{|c|}{ Bus Rider } \\
\hline & Alone & Pool & Alone & Pool & Alone & Pool \\
\hline Convenience & 9.3 & 2.9 & 9.0 & 3.7 & 8.9 & $4.4^{*}$ \\
\hline Reliability & 9.1 & 3.8 & 8.6 & 4.5 & 8.1 & 4.4* \\
\hline Comfort & 8.9 & 3.8 & 8.4 & 4.4 & 8.2 & $4.6^{*}$ \\
\hline Speed & 8.4 & 3.6 & 8.1 & 4.2 & 7.8 & $4.2^{*}$ \\
\hline Pleasantness & 8.1 & 4.5 & 7.9 & 5.2 & 7.2 & $5.6^{*}$ \\
\hline Safety & 7.7 & 4.6 & 7.5 & 5.4 & 6.7 & $4.9^{*}$ \\
\hline Expense & 5.8 & 3.0 & 6.8 & 3.0 & 7.4 & $3.1^{*}$ \\
\hline
\end{tabular}

Note-Alone $=$ drive alone. Pool $=$ carpool. $\quad{ }^{*} p<.01$ for drive alone versus carpool comparison.

and the last is a subjective cost measure. A 3 (commuter type) $\times 2$ (mode) ANOVA was performed on each of the six variables, with mode treated as a repeated measure.

The main effect of commuter type was significant only for expense $[F(2,667)=6.72, p<.001]$. Significant main effects of mode were found for all dependent variables, with $F_{\mathrm{s}}(1,666)$ ranging from 52.34 to 108.83 (all $p \mathrm{~s}<.001)$. Significant interactions of mode by commuter type were also found for all variables, except convenience, with $F_{\mathrm{s}}(2,667)$ ranging from 4.82 to 10.46 (all significant $p s<.01)$.

The main effects of mode (alone vs. pool) indicate that participants have more favorable attitudes toward driving alone than carpooling, with respect to both service characteristics and cost. The interaction effects can be seen by inspecting the ratings of each type of commuter toward each mode. Among the three groups, solo drivers rated the five service characteristics of driving alone highest and those for carpooling lowest. Carpoolers, on the other hand, rated all service characteristics of driving alone lower, and those for carpooling higher, than did solo drivers. Bus riders showed the least disparity between their ratings of driving alone and carpooling, consistently rating driving alone lower than did either of the other two groups.

Although attitude ratings differed reliably among the three types of commuters, the ranking of variables produced by these ratings is quite consistent across groups. This similarity may account for the inability of a discriminant analysis on these measures to differentiate between groups with better than $51 \%$ accuracy (carpoolers were correctly classified in only $36 \%$ of the cases).

As seen in Table 4, participants viewed carpooling more favorably in terms of its societal benefits, regardless of commuter type. Although reliable differences were found between driving alone and carpooling on all three measures, with $F_{\mathrm{s}}(1,667)$ ranging from 60.18 to 77.72 (all ps $<.001)$, no main effects of commuter type or interactions were found. Group membership was predicted with no greater than $34 \%$ accuracy using these data.

Based on the results of these analyses, we attempted to construct a multivariate model to predict current mode (i.e., commuter type) based on a combination of the so- 
Table 4

Commuters' Mean Attitude Ratings of the Societal Benefits of Carpooling and Driving Alone

\begin{tabular}{|c|c|c|c|c|c|c|}
\hline \multirow[b]{3}{*}{ Benefit } & \multicolumn{6}{|c|}{ Type of Commuter } \\
\hline & \multicolumn{2}{|c|}{ Solo Driver } & \multicolumn{2}{|c|}{ Carpooler } & \multicolumn{2}{|c|}{ Bus Rider } \\
\hline & Alone & Pool & Alone & Pool & Alone & Pool \\
\hline Save energy & 2.8 & 7.9 & 3.0 & 8.0 & 1.9 & $8.4^{*}$ \\
\hline Reduce pollution & 2.5 & 8.0 & 2.8 & 8.1 & 2.0 & $8.7^{*}$ \\
\hline $\begin{array}{l}\text { Reduce traffic } \\
\text { congestion }\end{array}$ & 2.4 & 8.0 & 2.5 & 8.2 & 2.1 & $8.8^{*}$ \\
\hline
\end{tabular}

Note-Alone $=$ drive alone. Pool $=$ carpool. $\quad{ }^{*} p<.01$ for drive alone versus carpool comparison.

cioeconomic and attitudinal variables. Discriminant analysis, performed on the variables that differed significantly among types of commuters in the foregoing univariate analyses, properly identified $71 \%$ of bus riders, $70 \%$ of carpoolers, and $58 \%$ of solo drivers.

\section{DISCUSSION}

The present results help to clarify the role of socioeconomic and demographic variables in mode choice. Our findings agree with national figures in showing that mass transit users have significantly lower incomes than automobile commuters. Although no significant difference in income was found between carpoolers and solo drivers, carpoolers tended to have lower incomes (Kostyniuk, 1982; Teal, 1987). The influence of economic factors is also expressed indirectly, in that bus use and carpooling are related to car availability, that is, having fewer cars than drivers per household (Teal, 1987; Tischer \& Dobson, 1979).

By themselves, however, socioeconomic variables were only fair predictors of carpoolers and bus riders, and the classification of solo drivers using these variables was generally poor. Since marital status differed between the carpoolers and solo drivers in our sample, this variable provides a key to distinguishing carpoolers from other car commuters; however, the two groups are similar in other characteristics. This may reflect a peculiarity of our sample in that an unusually high percentage (roughly $80 \%$ ) of the carpoolers belong to family carpools, and the characteristics of family carpoolers appear to be more similar to solo drivers than they are to nonfamily, or "external," carpoolers (McLeod et al., 1988, in press; Teal, 1987).

Participants' attitudes about the societal benefits of carpooling did not discriminate among groups, with all three groups of commuters highly rating the societal benefits of carpooling. Apparently, such attitudes do not affect behavior.

Attitudes toward service characteristics did nearly as well as socioeconomic variables in classifying the three types of commuters, and attitudes toward the importance of the automobile did better in some ways. That their inclusion in the model improved its predictive accuracy attests to the importance of such psychological variables in mode choice, independent of strictly economic considerations (Benjamin \& Sen, 1982; Tischer \& Dobson, 1977).

Nevertheless, all participants rated the value of an automobile for various trip purposes (except the work trip) about equally, and all three groups produced similar patterns of ratings with respect to the service characteristics and expense of carpooling and driving alone. Taken together, these results are consistent with previous studies showing that people think the benefits of driving far outweigh its costs (Baerwald, 1985; Margolin \& Misch, 1978).

One of the chief benefits of the automobile, in our view, is its ability to reduce costs, that is, information costs, which are usually ignored in economic models (McLeod, 1985). This becomes evident if we consider the situation in which a person who does not own a car wants to make a trip. Obviously, he/she needs to obtain information about how to get where he/she wants to go. First, what modes of transportation are available? Second, how much do they cost? If he/she chooses the bus, say, over a taxi, because of relative costs, then he/she must find out which bus route to take, where the bus stop is, and what time the bus comes. Just as trip time, including travel and waiting times, represents costs to the traveler, there also are costs to acquiring the information needed to make the trip.

It should be apparent that the amount of time and effort spent to arrange transportation on a trip-by-trip basis is much higher for someone without a car than for somebody who has one. The costs of acquiring information for each trip purpose, therefore, are higher. When we look at the data from bus riders, we see that the only trip purpose for which they rate the car low is the work trip. This is not surprising, since most transit systems are organized to serve this purpose, making the information costs for this purpose significantly lower for the user. However, the information costs for other trip purposes are high. For most people and for most purposes, therefore, the car is superior to other modes because it greatly reduces information costs.

Given this perspective, it does not seem likely that people's favorable attitudes toward individual use of the automobile can be readily changed, because these attitudes are deeply seated in the quality of service provided by the automobile, a level of service not provided by other transportation modes. Even if people believe that worthwhile societal goals or personal economic gains can be achieved by carpooling, mass transit, or some other form of ridesharing, using such modes may not be individually worthwhile given their total costs.

\section{REFERENCES}

Baerwald, T. J. (1985). Commuter attitudes toward ridesharing. Environments, 17, 96-99.

BehNKe, R., \& McLeod, M. (1984, January). Videotex, transportation and energy conservation. Paper presented at the Pacific Telecommunications Conference, Honolulu, HI.

Benjamin, J., \& Sen, L. (1982). Comparison of the predictive ability of four multiattribute approaches to attitudinal measurement. Transportation Research Record, 890, 1-6.

HARTGEN, D. T. (1974). Attitudinal and situational variables influencing urban mode choice: Some empirical findings. Transportation, 3 , 377-392.

Johnson, M. A. (1978). Attribute importance in multiattribute transportation decisions. Transportation Research Record, 673, 15-21.

KostyniUk, L. P. (1982). Demand analysis for ridesharing: State-ofthe-art review. Transportation Research Record, 876, 17-26.

MARGolin, J. B., \& Misch, M. R. (1978). Incentives and disincentives of ridesharing. Transportation Research Record, 673, 7-15.

McLeod, M. S. (1985, June). Reducing information costs to the public. Paper presented at the Videotex Conference, New York, NY. Mcleod, M. S., Jr., Flannelly, K. J., \& Henderson, B. H. K. (1988, January). An analysis of the commuting behavior of Hawai state employees working in downtown Honolulu. Paper presented at the meeting of the National Research Council, Transportation Research Board, Washington, D.C.

McLeod, M. S., Jr., Flannelly, K. J., \& Henderson, B. H. K. (in press). The commuting behavior of Hawaii state workers in Honolulu: Implications for TSM strategies. Transportation Research Record.

Paine, F. T., Nash, A. N., Hille, S. J., \& Brunner, G. A. (1969) Consumer attitudes toward auto versus public transport alternatives. Journal of Applied Psychology, 53, 472-480.

TEAL, R. F. (1987). Carpooling: Who, how and why. Transportation Research, 21A, 203-214.

Tischer, M. L., \& DoBson, R. (1979). An empirical analysis of behavioral intentions of single-occupant auto drivers to shift to high occupancy vehicles. Transportation Research, 13A, 143-158.

(Manuscript received May 20, 1988.) 